\title{
The Effects of the CALL Model on College English Reading Teaching
}

\author{
https://doi.org/10.3991/ijet.v12.i12.7954 \\ Dan Zhang, Xiaoying $\left({ }^{\bowtie}\right)$ Wang \\ Zhejiang University, Hangzhou, China \\ newworld272@126.com
}

\begin{abstract}
Computer Assisted Language Learning (CALL) is an important concept in English teaching method reform. College students' English reading ability is an important indicator in the evaluation on the college students' English proficiency. Therefore, this paper applies the CALL model in English reading teaching. Firstly, it introduces the application and development prospect of the CALL model, and analyzes its advantages and disadvantages; secondly, it analyzes the present situation of college English teaching and its influencing factors and then designs an application example to integrate the CALL model with different aspect of English reading. Finally, it analyzes the teaching results of college English reading under the CALL model. Therefore, in both theory and practice, this paper proves the effectiveness and innovativeness of the CALL model.
\end{abstract}

Keywords_CALL, English reading, teaching, example study

\section{Introduction}

In this highly informational 21st century, China is carrying out more and more frequent exchanges and cooperation with different countries in the world in science and technology and culture. Naturally, English, as the international language, is playing an increasingly important role in international exchanges [1]. Among all the English skills, English reading is perhaps the most basic one. With the rapid development of science and technology at home and abroad, a large number of complicated science and technology literature need to be read and translated. As a result, college students need to have efficient reading abilities so as to read as many foreign language literatures as possible and find as much information as they can within the limited time. [2]. Nearly two-thirds of the world's science literatures are written in English. Therefore, English reading is the main means by which people get to understand the development of the world. For college students, English reading is particularly important. It is an important way for college students to acquire English knowledge in colleges and also the main language skill that they will apply in their work and study after graduation. English reading ability is the foundation for English listening, speaking and writing skills and also an important channel for English language study [3]. 
In terms of nature and function, language is a multi-level code system that combines sound and meaning with speech sound or glyph as the material shell, vocabulary as the building block and grammar as the structure law [4]." College English teaching inevitably involves phonetic teaching. The wide application of multimedia technology has broken the deadlock situation of traditional "dumb English" teaching which weighs grammar and vocabulary over pronunciation. Usually under the traditional foreign language teaching method, teachers teach orally in class and students listen [5]. However, the inaccuracy of oral teaching and the limitations of sounds lead to great errors in student's imitation and pronunciation. What is more, students do not have many opportunities to listen and be corrected in time.

The CALL model just makes up for the deficiency of traditional college English reading teaching. On one hand, it facilitates dynamic exchanges in the teaching process; and on the other hand, it diversifies the teaching process with various computeraided equipment like language lab, multimedia classroom and computer corpus software, etc. This paper studies the effects of the CALL model on college English teaching and designs an application example to demonstrate the guiding significance of this model.

\section{Computer assisted language learning}

\subsection{Emergence and definition of CALL}

Computer Assisted Language Learning (CALL) made its first appearance in the U.S. in the 1960s, and since then, it has been upgraded with the rapid development of computer and network technologies [6]. The popularization of computer in various fields of society is also promoting the application of CALL in language listening, speaking, reading and writing. With students as the main target, CALL advocates the open teaching method to optimize the teaching effects. With the gradual development of CALL [7], so far a set of language teaching theories have been formed, as shown in Table 1.

Table 1. Language teaching theory of CALL

\begin{tabular}{|l|l|l|}
\hline \multicolumn{1}{|c|}{ Develop stage of CALL } & \multicolumn{1}{|c|}{ Teaching Theory } & \multicolumn{1}{c|}{ Basic content of teaching theory } \\
\hline Behaviorism CALL & Behaviorism learning theory & Repeated practice \\
\hline Communication CALL & Cognitiveist learning theory & $\begin{array}{l}\text { Cultivating learners' communicative compe- } \\
\text { tence through interaction }\end{array}$ \\
\hline Synthesize CALL & Constructivist learning theory & Learning is based on experience \\
\hline
\end{tabular}

\subsection{Characteristics and advantages of CALL}

The CALL teaching model is based on computer and network technologies. The following characteristics show it is a combination of computer and network technologies and modern education: 
1. Maximized resources utilization: it optimizes resources allocation, saves resources utilization time and arouses learning interest.

2. Independent learning behavior: it applies network technologies in distance education and has no constraint on online education [8].

3. Interactive learning: the interactions and exchanges between individual online learners can help improve their problem solving abilities.

4. Automated and personalized teaching model: as the computer network is two-way interactive, it can provide different learning programs for different learners in the classroom through the CALL platform and automatically evaluate the performance of students. In this way, the teaching and learning process is convenient and fast.

The application of the CALL model in language teaching can motivate learners' interest and enthusiasm, improve their learning efficiency and train their innovation capacity in learning.

\subsection{Application prospect of CALL in English reading}

This paper tries to discuss the application prospect of the CALL model in college English reading by analyzing the many problems in traditional education.

The traditional teaching model is teacher-centered, which means in reading learning activities, the teacher is the active participant while students are passive ones. Due to the differences in individual learners and their reading abilities, teachers' teaching methods and instructions are not suitable for everyone, resulting in a low knowledge acceptance rate [9] and making it very difficult to improve students' English reading skills. The traditional classroom teaching is neither fun nor innovative, and as a result, it is very difficult to exploit students' learning potentials and there are a lot of problems in college students' reading speed, basic knowledge and reading habits [10]. Statistics show that if Chinese college students read English articles at a speed of 140 words $/ \mathrm{min}$, they can only understand $54 \%$ of them. If they slow down the reading speed, they can improve their understanding rate. However, in English reading, it is important to read it fluently, so reducing the reading speed will make the short-term memory storage saturated and lead to information loss, and at last affect reading performance.

\section{CALL-based college English reading teaching}

\subsection{Teaching model design}

The main idea about the design of the teaching model and teaching process is to integrate the computer-aided teaching model with the traditional one to arouse students' learning interest and increase their initiatives.

Classroom demonstration model. Classroom demonstration is a traditional teaching model. It is one of the traditional "go-by-the-book" models. Usually it means that teachers use Office tools like Word, Power Point and Front Page to make simple 
editing of the teaching contents and present them in class [11]. Teachers can also insert materials like sounds, graphs and clip art related to the teaching contents to stimulate students' interest and imagination.

Multimedia and network aided interactive teaching model. Online real-time communication and interactions through network is a new teaching model based on computer network. Students can not only ask teachers questions through social software such as e-mail, Weibo, blog and instant chat software, but also discuss problems with other students. At the same time, teachers can also use this platform to post the language key points of the reading course on the bulletin board and students can use their spare time to view and preview knowledge points [12]. Another interactive teaching model is the distance learning system. According to statistics, so far there have been 45 online colleges approved by the Ministry of Education. In distance education, students are not constrained by time or space.

\subsection{Teaching process design}

With improving college students' English reading skill as the purpose, this paper divides the teaching process into three stages: reading preparation, fast reading and careful reading.

In the reading preparation stage, background knowledge is imported to stimulate students' imagination and interest so that they will read the article more carefully. In this stage, students get to know the purpose of this reading and eliminate the impacts from cultural differences and objective factors. Take Unit 1 Famous Universities in Integrated Coursebook 2 of Experiencing English for example. Here we give an audio material to introduce the world famous universities [13], as shown in Figure 1.

Then, as shown in Figure 2, we present five pictures to the students in class, arrange group study and assign a briefing task to each group, asking them to make a brief introduction of the pictures selected within 10 minutes, and at last select a winner. This method makes students feel involved in the learning activity and improves their concentration [14].

In the CALL model, by clicking the speaker icon in Figure 1, we can play the audio file of the text. On one hand, this can improve students' listening ability; on the other hand, this combination of images and sounds can help students integrate the background knowledge in their learning and thus improve their learning efficiency.

The CALL model is also applied in extended reading. The process flow chart, as shown in Figure 3 [15], can help achieve the application of the new teaching model.

In Figure 3, defining subject and importing scenario are the supplementary learning materials provided by the teacher according to the contents of the new course. This not only creates an optimal reading environment for students, but also encourages them to learn additional knowledge. Self-exploration and collaborative learning are the process where students collaborate with and learn from each other. In this process, the teacher only serves as a guide to advise students of the reading objectives and give them learning instructions, and students, as the main participants, fully utilize computer network information and resources to acquire and analyze information and carry out online communication via social software to understand others' pro- 


\section{Unit 1 \\ Famous Universities}

Directions: Listen to the following passage and try to fill the missing words. Click here to listen. 6

Famous universities are located all over the world, and they attract students from all over the world, too. Oxford and Cambridge are the two oldest universities in Britain with a history of Oxford 1._1100s. Princeton was established in 1746 and is 2. Princeton, New Jersey, a state on the east coast of America. MIT began in 1861 and is

located in another 3. _ state, Massachusetts. Stanford is a famous university in California. In 1891, Mr. and Mrs. Leland Stanford wanted to 4.__ a university in the west where young men and young women could 5.__ a degree. They donated many acres of land to the establishment of Stanford. It is one of the largest campuses in America today.

Harvard is the oldest university in America 6. many historic buildings and an 7. ___ of American history. Students 8. ___ Harvard have more than 40 areas of undergraduate studies to choose from. There are schools of medicine, business, design, law, public health, public policy, to 9. __ a few. First year students, called freshmen, are required to live on campus. Sophomores and upper classmen can choose off campus living in an 10 . __ or a house. There are many activities students can participate in from music to sports to student government.

Fig. 1. Introduction of famous universities

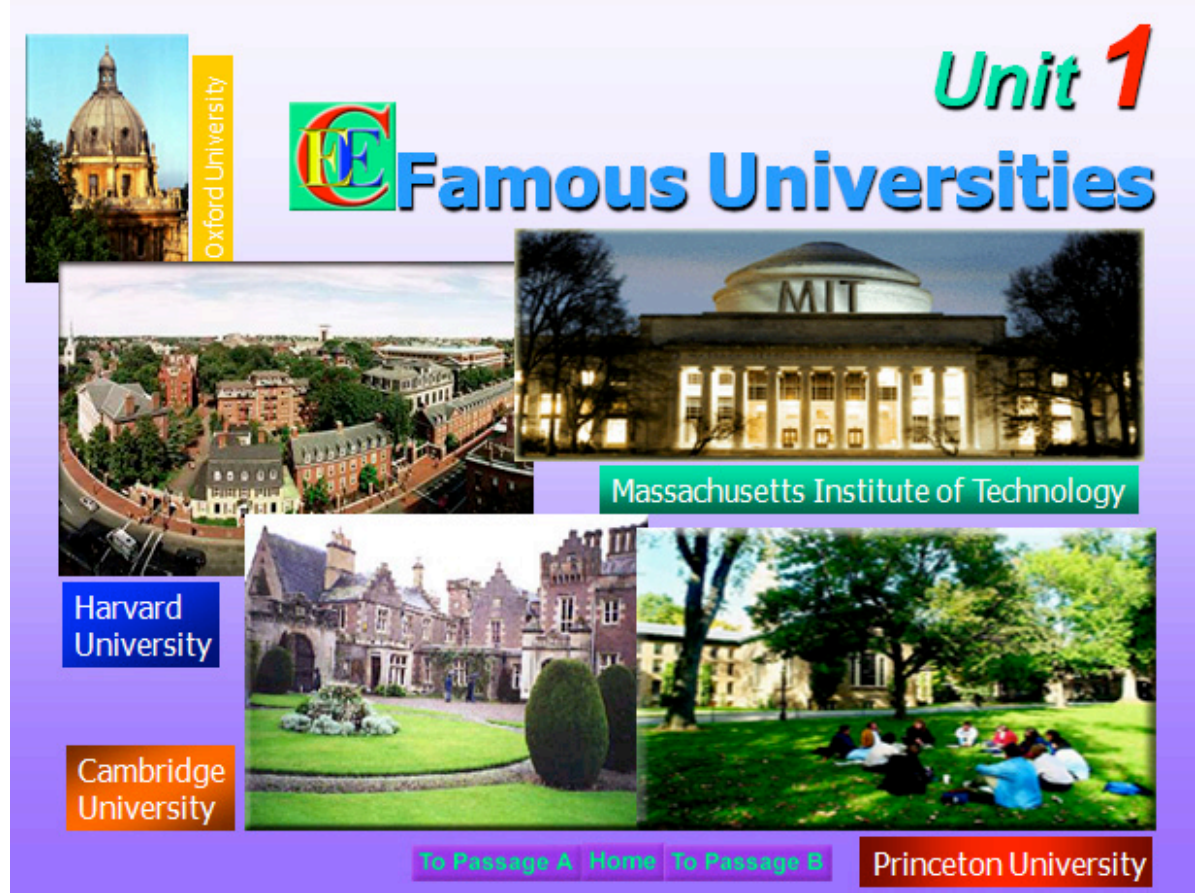

Fig. 2. Picture of famous universities around the world 


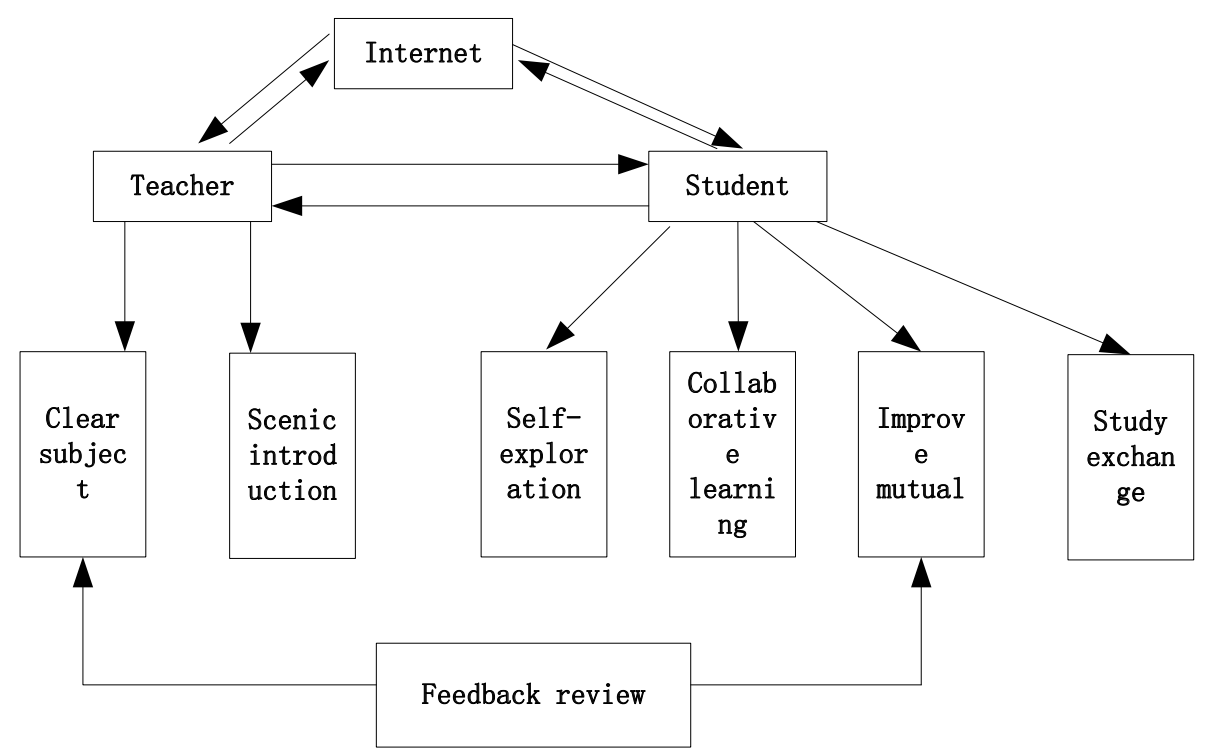

Fig. 3. New teaching model flow chart

gress in reading so that they can collaborate better. In the feedback review and learning exchange parts, the "teacher-computer-student" model achieves the interactions between students and teachers, and the "student-computer-student" model achieves the interactions among students. The feedback review part can give timely feedbacks on students' reading ability so that students can correct their own mistakes and shortcomings in a timely manner.

\section{$4 \quad$ Teaching experiment design and teaching effect analysis under the CALL model}

\subsection{Teaching experiment design}

Experimental objective. The aim of this experiment is to study the effects of the CALL model on improving students' reading abilities, changes in learning attitude and interest and the interaction effects between them through an 18-week comparative experiment. In this experiment, the independent variable is the teaching method and the dependent variable is the English reading ability.

Experimental subject. Participants in this experiment are 106 students from 2008 Legal English Class 1 and 2 (experimental class and control class) in Department of Foreign Languages of Shandong University of Political Science and Law. The experimental class and control class attend 3 English reading class every week, 2 of which are intensive reading and 1 is extensive reading. Before this experiment, these 106 students were under the traditional teaching model. In this experiment, the experiment 
class receives the "independent online learning + teacher face-to-face teaching" combined teaching under the CALL model for the first time [16]. The experiment group consists of 35 students with similar grades in Class 1 after test, and the control group consists of 35 also with similar grades in Class 2.

\subsection{Experimental method}

This experiment includes test and questionnaire survey. The test involves pretest and aftertest, of which the pretest is to test the English reading level of students before the new teaching method is adopted and the aftertest is to test that of students after one semester under the new teaching method. The questionnaire survey is to obtain the feedbacks from students on English reading teaching under the CALL model in order to have an idea of how student feel about the CALL model and how the evaluate their own learning effects.

\subsection{Specific experimental procedures}

1. Preparation: The preparation is to define the main contents to learn according to the characteristics of the experimental class and the control class and find the appropriate online learning resources. This stage mainly involves classroom participation and discussion on how to develop appropriate reading teaching plans under the CALL model.

2. Pretest: In the pretest, 2008 national CET reading comprehension questions were used. The pretest lasts 35 minutes, with a total score of 100 . There are 4 articles and 20 questions. The purpose of the pretest is to verify that there is not much difference between the English reading level of the two classes so as to ensure the accuracy of the test results.

3. Teaching implementation: In this stage, the CALL model is adopted to help learn intensive reading and extensive reading, improve students' abilities to use computer-aided teaching and observe and record the changes in students' learning interest and attitude.

4. Aftertest and data acquisition and analysis: After a semester is over, the students attend the aftertest, which consist of the 2009 national CET reading comprehension questions. The test lasts 35 minutes, with a total score of 100 . There are 4 articles and 20 questions. The scores and the questionnaires of the experimental class and the reference class are collected and analyzed.

\subsection{Experimental result analysis}

For the experimental class: the data-driven learning method based on computer corpus is adopted in college English vocabulary teaching. 1. Read the vocabulary to get students familiar with it and correct their pronunciations; 2. Show concordance sample sentences to students; 3 . Assign classroom tasks related to the word collocation; 4. Encourage independent thinking and summarizing word usage patterns; 5 . Use new words to make sentences to enhance students' understanding of the vocabulary. 
The aftertest is carried out to verify whether the experimental assumption proposed in this paper holds true. Beside the aftertest, questionnaire survey is also conducted among the students in the experimental group to find out how the computer-corpusbased teaching method improves their English vocabulary level and their independent vocabulary learning organizing abilities

\subsection{Experimental data comparison and analysis}

Summary and analysis of the test scores. The pretest results of the control group and the experimental group are shown in the table below:

Table 2. Pretesting result

\begin{tabular}{c|c|c|c|c}
\hline Class & N & Mean & Standard deviation & Standard error mean \\
\hline Control class & 35 & 49.86 & 11.08 & 1.873 \\
\hline Test class & 35 & 49.43 & 12.353 & 2.088 \\
\hline
\end{tabular}

From Table 2, we can see that in the pretest, the differences are very small between the mean scores, standard deviations and the standard deviations of mean score of the control group and the experimental group, indicating that the students tested in the pretest have similar English levels, which meet the initial requirement for the comparative experiment.

The aftertest results of the control group and the experimental group are shown in the table below:

Table 3. Posttesting result

\begin{tabular}{c|c|c|c|c}
\hline Class & N & Mean & Standard deviation & Standard error mean \\
\hline Control class & 35 & 60.86 & 10.253 & 1.733 \\
\hline Test class & 35 & 73.86 & 9.242 & 1.562 \\
\hline
\end{tabular}

From Table 3, we can see that the aftertest scores of the experimental group are much higher than those of the control group - the mean score is 13 points higher, which preliminarily indicates that the CALL model has a positive effect on students' English reading.

In order to show the differences in the results more clearly, we perform $\mathrm{T}$ test on the results according to the statistical testing principle, which is to calculate the significance values of the two mean differences to show the difference between the experimental group and the control group.

Table 4. Test results data display

\begin{tabular}{c|c|c|c}
\hline \multicolumn{2}{|c|}{ Project } & Pretesting & Aftertest \\
\hline \multirow{2}{*}{ Test class } & Mean & 49.43 & 73.86 \\
& Standard deviation & 12.353 & 9.242 \\
\hline \multirow{2}{*}{ Control class } & Mean & 49.86 & 60.86 \\
\hline \multicolumn{2}{c}{ Standard deviation } & 11.080 & 10.253 \\
\hline \multicolumn{2}{c}{ Significance P Value } & 0.151 & 7.464 \\
\hline
\end{tabular}


From Table 4, we can see that for the pretest scores, $\mathrm{P}>0.05$, meaning that the difference is not significant, while for the aftertest scores, $\mathrm{P}<0.01$, meaning the difference is significant. The English reading levels of the experimental group and the control group are changed from being similar to being significantly different, which further proves that the CALL model is useful in improving college students' English reading skills.

Effects of the CALL model on students' interest and learning attitude. Questionnaire survey is conducted on the students before and after the experiment. The questionnaire contains 10 questions, each with a score of $1 \sim 5$ point. We use the SPSS software to analyze the changes in students' interest and learning attitude in the experiment, as shown in Table 5.

Table 5. Interest and attitude contrast before and after test

\begin{tabular}{l|c|c|c|c|c}
\hline \multicolumn{1}{c|}{ Project } & T & Mean & Std.Deviation & df & Sig(2-tailed) \\
\hline Before and after test(Interest) & -6.55 & -6.49 & 5.858 & 34 & .000 \\
\hline Before and after test(Attitude) & -4.613 & -3.66 & 4.690 & 34 & .000 \\
\hline
\end{tabular}

From the table we can see that neither of the T values are within the $[-2.101,2.101]$ interval, indicating that changes are significant. Therefore, through the English reading teaching under the CALL model, students' learning interest and attitude have significantly changed. The change in interest is greater than that in attitude, indicating that the CALL model is more effective in stimulating students' interest.

\section{Conclusions}

This paper, based on the CALL model, explores the effects of computer-aided learning on improving college students' English reading performance, integrates computer technologies with college students' English reading teaching and gives an example to analyze and verify that the CALL model plays positive roles in improve college students' English level. The conclusions and the innovations of this paper are summarized as follows:

1. The CALL model plays positive roles in improving college students' English reading performance and changing their learning interest and attitude;

2. Computer-aided teaching methods will be continuously upgraded with the development of network and computer technologies; therefore, college English teaching should adopt new methods in a timely manner.

3. In the experimental analysis, both the mean value and the T-test methods are used to provide more convincing data to prove the effects of the CALL model on teaching. 


\section{References}

[1] Cheng, P.W., Tian, Y.J., Kuo, T.H., Sun, K.T. (2016). The relationship between brain reaction and English reading tests for non-native English speakers. Brain Research, 1642: 384-388. https://doi.org/10.1016/j.brainres.2016.04.044

[2] Mei, L., Xue, G., Lu, Z.L., Chen, C., Wei, M., He, Q., et al. (2015). Long-term experience with Chinese language shapes the fusiform asymmetry of English reading. Neuroimage, 110: 3-10. https://doi.org/10.1016/j.neuroimage.2015.01.030

[3] Yang, Z., Wang, C., Feng, L., Li, S., Tao, S. (2016). Unsuccessful letter-sound integration in English reading by native Chinese speakers: Evidence from an event related potentials study. Science Bulletin, 61(24): 1855-1864. https://doi.org/10.1007/s11434-016-1078-y

[4] Wik, P., Hjalmarsson, A. (2009). Embodied conversational agents in computer assisted language learning. Speech Communication, 51(10): 1024-1037. https://doi.org/10.1016/j.s pecom.2009.05.006

[5] Wang, H., Waple, C.J., Kawahara, T. (2009). Computer assisted language learning system based on dynamic question generation and error prediction for automatic speech recognition. Speech Communication, 51(10): 995-1005. https://doi.org/10.1016/j.specom.2009.03 .006

[6] Ferrer, L., Bratt, H., Richey, C., Franco, H., Abrash, V., Precoda, K. (2015). Classification of lexical stress using spectral and prosodic features for computer-assisted language learning systems. Speech Communication, 69: 31-45. https://doi.org/10.1016/j.specom.2015.02 .002

[7] Makwana, V.N. (2011). Development of computer assisted language learning package for instruction of 'parts of speech' of English language. International Journal for Parasitology, 26(11): 1295-1303.

[8] Hew, S.H. (2003). A study on the effectiveness and usefulness of Aga and IVF in Japanese computer-assisted language learning (jcall). Analytical Sciences, 7(7): 377-380.

[9] Wang, L., Qian, Y., Scott, M., Chen, G., Soong, F. (2012). Computer-assisted audiovisual language learning. Computer, 45(6): 38-47. https://doi.org/10.1109/MC.2012.152

[10] Abufanas, O. (2013). Computer aided language learning system for Arabic for second language learners. Computer. 23: 12-21.

[11] Shield, L., Kukulska-Hulme, A. (2008). Special issue of recall on mobile assisted language learning. Folia Zoologica, 57: 90-99.

[12] Arias, J.P., Yoma, N.B., Vivanco, H. (2010). Automatic intonation assessment for computer aided language learning. Speech Communication, 52(3): 254-267. https://doi.org/10.1016/j.specom.2009.11.001

[13] Rahimi, M., S., F.H.K. (2011). The impact of computer-based activities on Iranian highschool students' attitudes towards computer-assisted language learning. Procedia Computer Science, 3: 183-190. https://doi.org/10.1016/j.procs.2010.12.031

[14] Wang, S., Heffernan, N. (2010). Ethical issues in computer-assisted language learning: perceptions of teachers and learners. British Journal of Educational Technology, 41(5): 796-813. https://doi.org/10.1111/j.1467-8535.2009.00983.x

[15] Yang, L. (2012). Study on reform of college English stratified teaching based on schoolbased characteristics. English Language Teaching, 5(5). https://doi.org/10.5539/elt.v5n5p $\underline{62}$

[16] Kozar, O. (2016). Perceptions of webcam use by experienced online teachers and learners: A seeming disconnect between research and practice. Computer Assisted Language Learning, 29(4): 1-11. https://doi.org/10.1080/09588221.2015.1061021 
Paper-The Effects of the CALL Model on College English Reading Teaching

\section{$7 \quad$ Authors}

Dan Zhang is with Zhejiang University, Hangzhou 310058, China.

Xiaoying Wang is with Zhejiang University, Hangzhou 310058, China.

Article submitted 09 November 2017. Published as resubmitted by the authors 10 December 2017. 